\title{
EFFECT OF BUNDLE ORIENTATION ON TRANSMISSION LINE AUDIBLE AND RADIO NOISE
}

\author{
Vernon L. Chartier, Fellow, IEEE \\ David E. Blair, Senior Member, IEEE \\ Bonneville Power Administration \\ Division of Laboratories \\ Vancouver, WA 98666-0491
}

\author{
Richard D. Stearns, Member, IEEE \\ Douglas J. Lamb, Member, IEEE \\ Bonneville Power Administration \\ Division of Electrical and Electronic Engineering \\ Portland, OR 97208-3621
}

\begin{abstract}
A bundle of four conductors may be used for the next generation of 500-kV lines at the Bonneville Power Administration (BPA). Among the many questions that needed answers were (a) the optimal orientation of the bundle to minimize the audible (AN) and radio noise (RI) and (b) whether trapezoidal conductors behaved differently than conventional stranded conductors. This paper shows the results of comparative tests conducted in BPA's high voltage laboratory comparing the RI and AN from 4 Bunting (conventional round rod) and $4 \mathrm{Hood}$ (trapezoidal) conductors oriented either in a square or a diamond configuration. To make the results more useful, similar tests were conducted on 2 Bunting and 2 Hood conductors oriented either horizontally or vertically and on 3 Bunting and 3 Hood conductors oriented in a vee or an inverted vee configuration. Tests on single Bunting and Hood conductors were also conducted. The tests showed that within the accuracy of noise measurements bundle orientation has little effect on the AN or RI and that the conventional Bunting and the trapezoidal Hood conductors have essentially the same noise performance.
\end{abstract}

Keywords: Corona, audible noise, radio noise, transmission lines, bundle orientation.

\section{INTRODUCTION}

In the design of the next generation of $500-\mathrm{kV}$ lines on the BPA transmission system, three of the primary goals have been to (1) minimize life-cycle costs, (2) keep the audible noise (AN) levels below $50 \mathrm{dBA}$, and (3) increase electrical capacity for future lines. The life-cycle cost is dominated by the cost to construct the line and the cost to maintain and operate it [1]. The resistive losses in the con-

94 WM 056-2 PWRD A paper recommended and approved by the IEEE Transmission and Distribution Committee of the IEEE Power Engineering Society for presentat ion at the IEEE/PES 1994 Winter Meeting, New York, New York, January 30 - February 3, 1994. Manuscript submitted July 29, 1993; made available for printing December 6, 1993. ductor heavily influence the operating costs of the line. BPA's most recent $500-\mathrm{kV}$ designs meet the $50 \mathrm{dBA}$ AN criteria at elevations close to sea level, but can not meet them at higher elevations. As is known, the $\mathrm{AN}$ increases about $1 \mathrm{~dB}$ per 300 meter increase in elevation [2]. Because of these three major design considerations, BPA for the first time has been considering the use of four conductor bundles.

A question that kept coming up during the discussions on the use of a four conductor bundle was the optimal orientation of the bundle from an AN standpoint, because for mechanical reasons, many engineers prefer arranging the conductors in a diamond rather than in a square configuration [3]. There is quite a bit of data in the technical literature giving the AN and RI performance of four conductor bundles arranged in a square [4-8]; however, such data essentially does not exist for the diamond arrangement.

The internal BPA Committee that is looking at the next generation of $500-\mathrm{kV}$ lines also was interested in using the new trapezoidal wire conductors that had been developed by BPA engineers [1]. The corona performance of this new conductor was expected to be the same as a conventional conductor if they both had the same diameter. However, like the question of the optimal orientation of the conductor bundle, no data comparing the performance of conventional and trapezoidal conductors could be found. To confirm that there was no difference between these two types of conductors, measurements were also made comparing the AN and RI performance of trapezoidal Hood conductors (diameter, $33.0 \mathrm{~mm}, 1.300^{\prime \prime}$ ) and conventional Bunting conductors $\left(33.1 \mathrm{~mm}, 1.302^{n}\right)$ arranged in two, three and four conductor bundle arrangements as well as singly.

The purpose of this paper is to report the results of the tests that were conducted in BPA's High Voltage Laboratory in Vancouver, WA to answer the above questions. To make the tests more useful to transmission line designers, single conductors and two and three conductor bundles were also tested. The two conductor bundles were tested in vertical and horizontal orientations and the three conductor bundles were tested in vee and inverted vee orientations. 


\section{BACKGROUND}

Conductors used on the BPA 500-kV transmission system have evolved from a large single conductor to three conductor bundles between 1968 and the present. The first $500-\mathrm{kV}$ line used a single $63.5 \mathrm{~mm}$ ( $2.5 \mathrm{in}$.) conductor which resulted in a large number of AN complaints [9]. The second generation conductor configuration consisted of two Chukar conductors oriented horizontally. This conductor had an outside diameter of $40.7 \mathrm{~mm}(1.602 \mathrm{in}$.). Whereas the single conductor was used primarily on flat configured towers, the two conductor bundle was primarily used on a delta configured tower. It should be noted that on lines subjected to severe aeolian vibration, a drop link has been used to place one of the two conductor bundles in a lower position. The third generation conductor configuration was three Bunting conductors oriented in a vee arrangement. Using this bundle on a single circuit $500-\mathrm{kV}$ line at lower elevations reduced the $\mathrm{AN}$ at the edge of the right-of-way to less than $50 \mathrm{dBA}$ which is the present $\mathrm{AN}$ design criteria at BPA. However, using this conductor on some of BPA's double circuit designs or at higher elevations produces AN that exceeds the $50 \mathrm{dBA}$ limit. A fourth generation of conductors was used on the Colstrip $500-\mathrm{kV}$ double circuit line [9]. For this line three Seahawk conductors $(40.7 \mathrm{~mm}$ in diameter) were used with the conductors oriented in a vee. Using this conductor bundle on either single or double circuit lines at low elevations gives AN levels that are less than $50 \mathrm{dBA}$. However, at the higher elevations that exist in Montana and some of the passes in the Cascade Mountains, the AN from lines using this conductor would exceed the $50 \mathrm{dBA}$ noise criteria. For the next generation of $500-\mathrm{kV}$ lines either four Hood or four Bunting conductors are being considered. The Hood conductor is a trapezoidal stranded conductor which "reduces air void area by 80 percent over conventional round rod conductors, allowing a denser packing of conducting material and greater efficiency through increased conductance and/or reduced tower loads" [1].

\section{Literature Review}

The technical literature is lacking in information on the effect of bundle orientation on conductor corona performance. On page 280 of EPRI's "Red Book" there is a brief discussion on bundle orientation [10]. It basically says that there is no appreciable effect for bundles with 3 or more conductors; however, for bundles of two subconductors the vertical configuration is $1.5 \mathrm{~dB}$ noisier than the horizontal bundle. This information appears to be based upon theoretical considerations rather than on experimental evidence since it is difficult to detect AN differences as small as $1.5 \mathrm{~dB}$ from corona tests either in the laboratory or on full-scale lines.

\section{TEST SETUP AND TEST EQUIPMENT}

Fig. 1 shows the basic test setup. Five Bunting and five Hood, $12.2 \mathrm{~m} \mathrm{(40} \mathrm{ft.)} \mathrm{long} \mathrm{test} \mathrm{conductors} \mathrm{terminated} \mathrm{in}$ "eye" compression fittings were fabricated for use as test specimens. The appropriate number of conductors were connected to main support plates inside lattice corona ring assemblies. In order to rotate the test assembly while the conductor was energized an axle spindle was bolted to these plates. As shown in Fig. 1 the test assembly was tensioned both vertically and horizontally since the laboratory walls could only support a tension of $907 \mathrm{~kg}(2000 \mathrm{lb}$.). All tests were conducted with the assembly raised to a height of

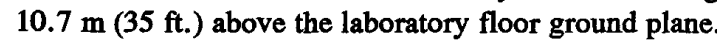

Fig. 2 show the cross section of a trapezoidal (TW) conductor and a conventional round rod (RR) conductor [1] Fig. 3 shows the orientations of the conductors that were tested.
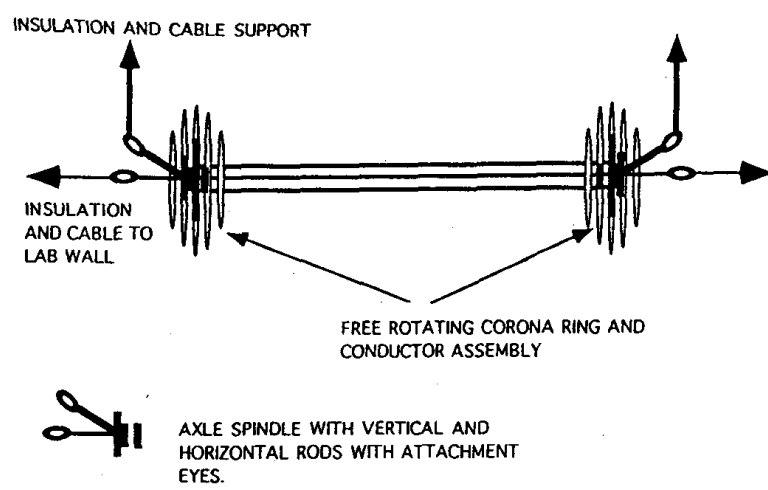

Fig. 1 Test setup
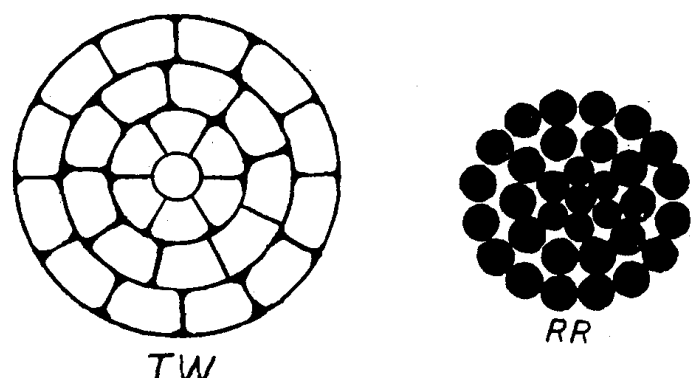

Fig. 2 Typical configuration for trapezoidal (TW) and conventional round rod ( $R R$ ) conductors 


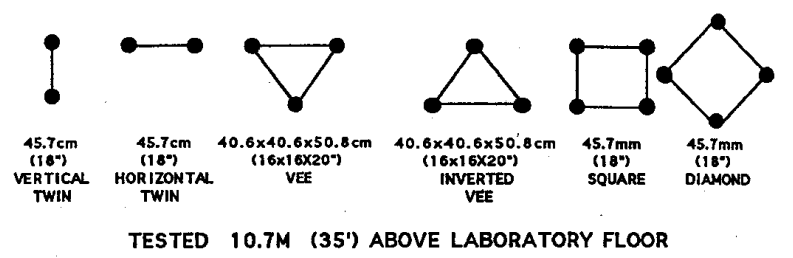

CONDUCTOR SPECIFICATIONS

BUNTING - $\quad 33.1 \mathrm{~mm}\left(1.302^{\circ}\right)$ ACSR

HOOD - $\quad 33.0 \mathrm{~mm}\left(1.300^{\circ}\right)$ AAC (TW)

Fig. 3 Conductor orientations tested

An $45.7 \mathrm{~cm}$ (18 in.) conductor spacing arrangement was used for both the twin and quad configurations. For triple bundle configurations the standard BPA $50.8 \mathrm{~cm}(20$ in.) $x$ $40.6 \mathrm{~cm}$ (16 in.) $\times 40.6 \mathrm{~cm}$ arrangement was used. An

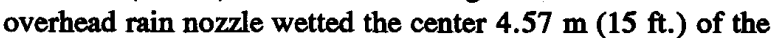
test conductor(s) at a rate of approximately $4.5 \mathrm{~mm} / \mathrm{minute}$. A rope on a hot stick was tied around one of the mounting plates so that the test fixture could be rotated while energized and while the spray system was on which made it possible to quickly determine both by ear and by measurements if the AN changed between the two orientations. This capability minimized the time delays which would have been needed to lower the test fixture and reorient the conductors. Such time delays could have affected the results by introducing different test conditions.

Two B\&K noise analyzers were used to measure the AN. Meter no. 1 was a model 4426 and meter no. 2 was a model 2230. Both meters used $12.7-\mathrm{mm}$ model 4155 condenser microphones. The microphone on meter no. 1 was on the end of a 30-m cable. The microphone for meter no. 2 was connected directly to the meter. Both meters were set for Aweighted measurements. Meter no. 2 had the additional capability of measuring octave bands.

The microphones were located 6.1-m laterally and 10.7-m radially from the centerline of the conductor (bundle) at midspan and at a height of $1.5 \mathrm{~m}$ above the floor. The two microphones were separated by approximately $1.5 \mathrm{~m}$.

The radio influence voltage (RIV) was measured at 834 kHz using a Singer Model NM25T RI and field intensity meter set for quasi-peak (QP) connected to the standard Laboratory NEMA 107-1987 NEMA Circuit [11].

The generally accepted accuracy for conducting AN and RI measurements is $\pm 2 \mathrm{~dB}$.

\section{TEST PROCEDURE}

It is well known that new conductors have higher AN levels than aged conductors $[12,13]$. This is because water beads on the new conductors whereas on aged conductors the water flows to the bottom and forms a drip line. For the purpose of comparison tests were conducted on the conductors in both a new and "aged" condition. After the tests on the new conductors were completed, four of the five conductors of each type were aged by steam cleaning them with tap water [13].

The following was the general procedure used throughout the AN tests:

1. Barometer and Indoor/Outdoor temperature readings were recorded;

2. Laboratory ambient noise was measured;

a. Meter no. 1 in dBA

b. Meter no. 2 in dBA

c. Meter no. 2 in dB, $8 \mathrm{kHz}$ octave band.

3. The water was turned on and each of the measurements in step 2 were repeated;

4. The $60-\mathrm{Hz}$ power supply circuit breaker was closed and each of the measurements in step 2 were repeated;

5. The voltage was raised to the initial test voltage and each of the measurements in step 2 were repeated. Tests for the single and twin conductor arrangements started at 200 kV. Tests for triple and quad arrangements started at 250 $\mathrm{kV}$.

6. The voltage was then raised in steps of $25 \mathrm{kV}$ to $450 \mathrm{kV}$, and all three measurements shown in step 2 were made at each level;

7. After at least $1 / 2$ hour, the test was repeated until a total of three runs were completed for each configuration. The results of the three tests were then averaged to obtain the final value for each test level.

On several occasions the AN was observed and measured at one voltage while the bundle was quickly rotated from one orientation to the other orientation.

The RIV was measured in steps of $50 \mathrm{kV}$ to $500 \mathrm{kV}$, but only on the "aged" conductors.

\section{TESTS RESULTS}

No difference in AN could be heard or measured when the bundles were quickly rotated between orientations while the voltage and spray system were on. This simple, but very effective test confirmed that bundle orientation had little effect on AN. As expected the most stable AN data were the $8 \mathrm{kHz}$ measurements since A-weighted measurements are affected by other man-made noise sources. Most man-made AN falls off quite rapidly with octave band frequency, whereas corona noise as measured with an octave band analyzer has a flat frequency response. Therefore, the higher octave band frequencies are a truer measure of the "bacon frying" noise created by conductor corona. Figs. 4 and 5 show the results of the wet $8 \mathrm{kHz}$ AN tests on the new and "aged" Hood and Bunting conductors, respectively 
arranged as single conductors and two, three and four conductor bundles. The A-weighted curves were very similar, but a bit more scattered [14].

As can be seen in Figs. 4 and 5, the bundle orientation had very little effect on AN irrespective of whether the bundle was made up of Bunting or Hood conductors. Also, very little difference can be seen in the AN between the Hood and Bunting conductors except for the AN measurements made on the single aged conductors (Fig. 5).

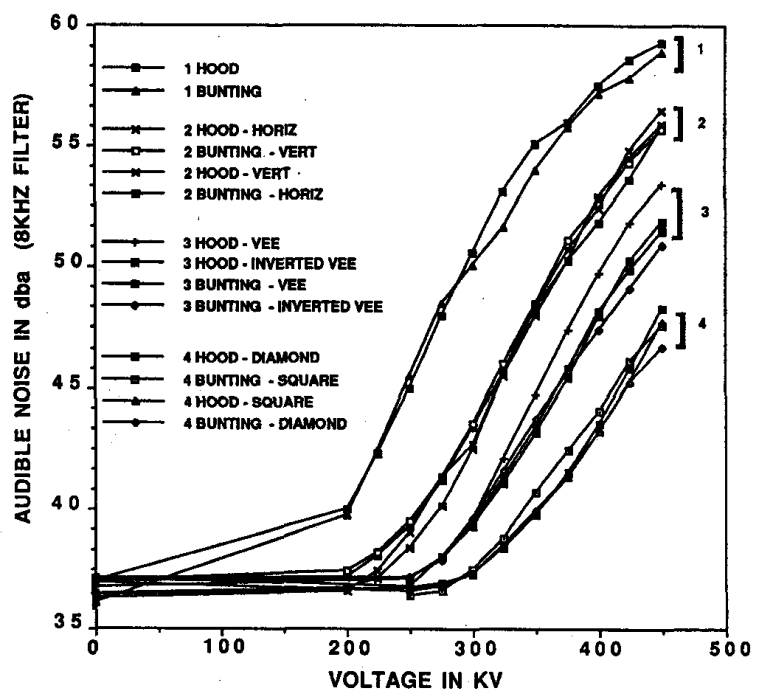

Fig. 4 Wet $8 \mathrm{kHz}$ AN tests on new conductors

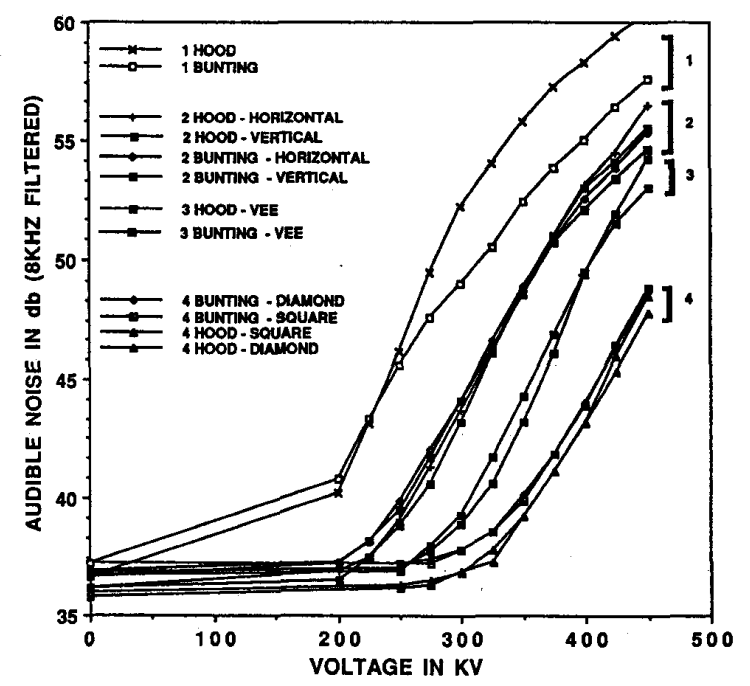

Fig. 5 Wet $8 \mathrm{kHz}$ AN tests on "aged" conductors
We aren't sure why the aged Hood conductor was a few $\mathrm{dB}$ noisier than the aged Bunting conductor at voltages above $250 \mathrm{kV}$, but it is only of academic interest since single conductors of this size would not be used at line-ground voltages above $250 \mathrm{kV}$.

Fig. 6 shows the results of RIV tests on the aged bundled conductors, and like the AN data the orientation of the bundle had very little influence on the RIV.

The important data in these figures are the measurements at conductor surface gradients that are close to what would be used on actual lines. The single Bunting or single Hood conductors are typically used on $230 \mathrm{kV}$ lines whereas two Bunting or two Hood conductors would typically be used on $345 \mathrm{kV}$ lines. As was discussed earlier, BPA has used three Bunting conductors on single circuit and double circuit 500 $\mathrm{kV}$ lines. The conductor surface gradients on all these lines depending upon their design, vary between 14 and 18 $\mathrm{kV} / \mathrm{cm}$. Table I shows a comparison of the A-weighted and $8 \mathrm{kHz}$ octave band data at conductor surface gradients of 14, 16 and $18 \mathrm{kV} / \mathrm{cm}$ for the two, three and four conductor bundles. Again, the bundle orientation and the type of conductor had very little influence on the AN.

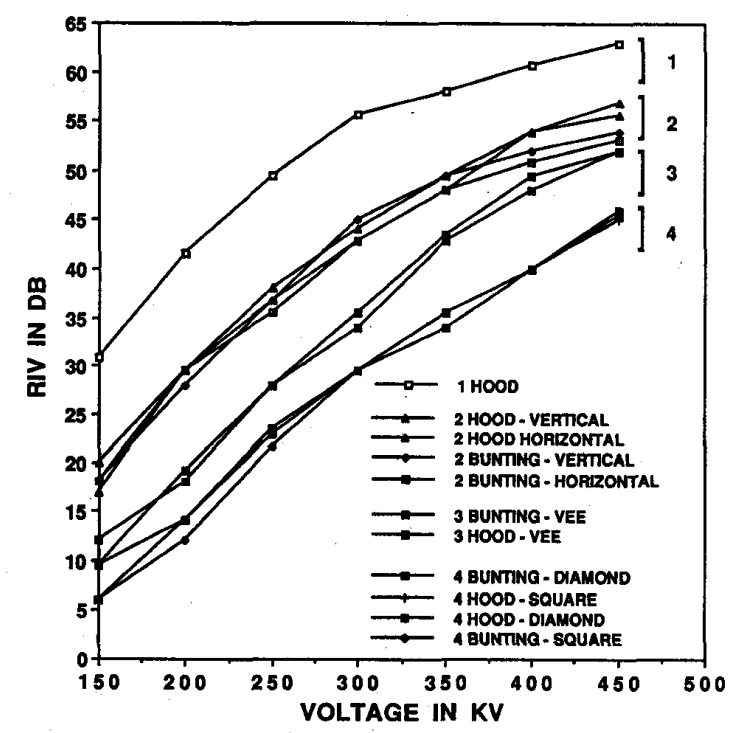

Fig. 6 Wet RIV tests at $834 \mathrm{kHz}$ on "aged" conductors 
TABLE I

COMPARISON OF AUDIBLE NOISE DATA AT THREE CONDUCTOR SURFACE GRADIENTS

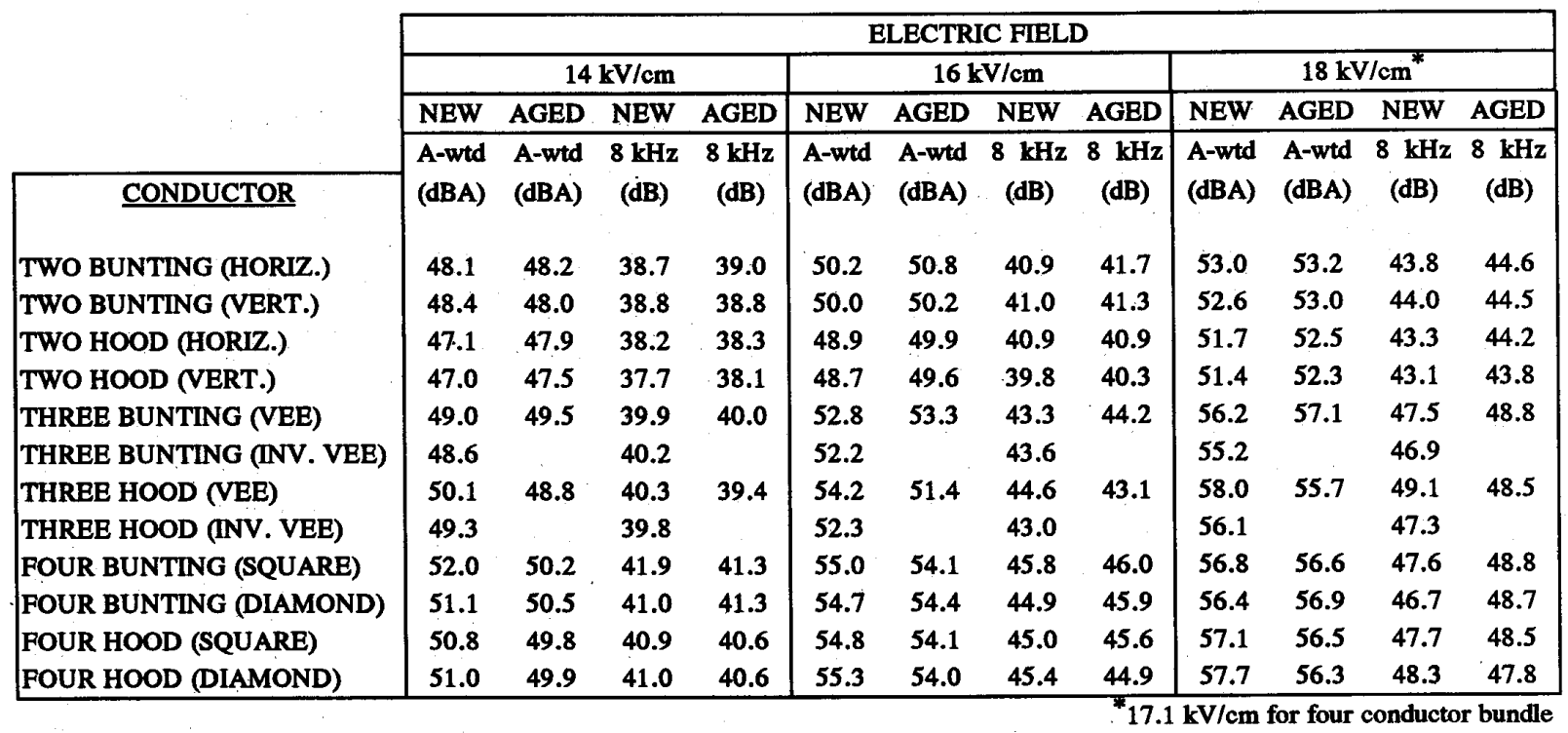

\section{CONCLUSIONS}

1. No consistent difference in the audible or radio noise performance under artificial rain conditions could be found between the 4 conductor bundle in either the square or diamond arrangement, the three conductor bundle in either the vee or inverted vee arrangement, or the two conductor bundle in either the horizontal or vertical arrangement.

2. No consistent difference in the audible or radio noise performance under artificial rain conditions could be found between the conventional Bunting conductor or the trapezoidal Hood.

3. It is not clear that the above conclusions are valid for dry conductors since it is impossible to make valid dry conductor measurements on extremely short conductors in high voltage laboratories. This is a moot point for $\mathrm{AN}$ since AN during fair weather for lines operating at normal conductor surface gradients is well below $40 \mathrm{dBA}$. However, many radio noise limits are based upon fair weather. The effect of bundle orientation on the fair weather RI performance would have to be validated on either fullscale test or operating lines.

\section{ACKNOWLEDGMENT}

The authors wish to acknowledge the contribution of Kent MacKebon for his overall efforts to the success of this test program; especially in the building and setting up of the free rotating corona ring and conductor assembly.

\section{REFERENCES}

[1] J. L. Reding, "Development and installation of BPA's new generation transmission conductors, "IEEE Transactions on Power Delivery, vol. PWRD-2, no. 3, July 1987, pp. 917-923.

[2] V. L. Chartier, L. Y. Lee, L. D. Dickson, K. E. Martin, "Effect of high altitude on high voltage AC transmission line corona phenomena, " ibid., no. 1, Jan 1987, pp. 225-237.

[3] R. S. Wolfe, E. S. Zobel, "Engineering of 430 miles of two parallel $500 \mathrm{kV}$ transmission lines," 1979 IEE Conference on Progress in Cables and Overheads Lines for $220 \mathrm{kV}$ and Above, pp. 135-141.

[4] R. Lacroix and H. Charbonneau, "Radio interference from the first $735-\mathrm{kV}$ line of Hydro-Quebec, "IEEE 
Transactions on Power Apparatus and Systems, vol. PAS-87, no. 4, April 1968, pp. 932-939.

[5] V. L. Chartier, D. F. Shankle, N. Kolcio, "The Apple Grove $750 \mathrm{kV}$ Project: statistical analysis of radio Influence and corona-loss performance of conductors at $775 \mathrm{kV}, "$ ibid., vol. PAS-89, no. 3, May/June 1970, pp. 867-881.

[6] N. Kolcio, B. J. Ware, R. L. Zagier, V. L. Chartier, F. M. Dietrich, "The Apple Grove $750 \mathrm{kV}$ Project: statistical analysis of audible noise performance of conductors at $775 \mathrm{kV}, "$ ibid., vol. PAS-93, no. 3, May/June 1974, PP. 831-840.

[7] N. Kolcio, J. Di Placido, R. J. Haas, D. K. Nichols, "Long term audible noise and radio noise performance of American Electric Power's Operating $765 \mathrm{kV}$ lines," ibid., vol. PAS-98, no. 6, Nov./Dec. 1979, pp. 1853-1859.

[8] N. Giao Trinh, P. Sarma Maruvada, J. Flamand, and J. R. Volotaire, "A study of the corona performance of Hydro Quebec's 735-kV lines," ibid., vol. PAS-101, no. 3, March 1982, pp. 681-690.

[9] D. E. Perry, "An analysis of transmission line audible noise levels based upon field and three-phase test line measurements," ibid., vol. PAS-91, no. 3, May/June 1972, pp. 857-864, .

[10] Transmission Line Reference Book - $345 \mathrm{kV}$ and Above/Second Edition, Electric Power Research Institute, Palo Alto, California, 1982.

[11] "Methods of Measurement of Radio Influence Voltage (RIV) of High-Voltage Apparatus," NEMA Standards Publication No. 107-1987.

[12] M. G. Comber, R. J. Nigbor, "Audible noise performance of regular and asymmetric bundles and effects of conductor aging on Project UHV's three-phase test line," IEEE Transactions on Power Apparatus and Systems, vol. PAS-98, no. 2, March/April 1979, pp. 561572.

[13] J. R. Booker, "Natural Aging of Non-Energized Aluminum Conductors," IEEE Transactions on Power Delivery, vol. PWRD-1, no. 4, October 1986, pp. 269-274.

[14] D. E. Blair, "60 Hz Audible Noise Test on Bunting and Hood Conductors," U. S. Department of Energy -
Bonneville Power Administration, Division of Laboratories Report No. ELE 91-84, May 15, 1992.

Vernon Lee Chartier (S'62, M'64, SM'72, F'80) was born in Fort Morgan, Colorado on February 14, 1939. He received the B.S. degrees in electrical engineering and business from the University of Colorado, Boulder in 1963.

From 1963-1975 he was with the Advanced Systems Technology Department of the Westinghouse Electric Corporation in East Pittsburgh, Pennsylvania where he was engineer-in-charge of the Apple Grove 750-kV Project and was this Department's principal consultant to the electric utility industry on the effects of electromagnetic fields and corona associated with high voltage transmission lines.

In 1975 he joined the Division of Laboratories of the Bonneville Power Administration where he was associated with the Lyons $1200-\mathrm{kV}$ Project until it's closing in the early 1980's. Since 1979 he has been BPA's Principal Engineer, High Voltage Phenomena where he has been responsible for several high voltage research projects.

Mr. Chartier is a member of the USNC of IEC; Technical Advisor to the USNC of IEC on matters pertaining to CISPR Subcommittee C (High Voltage Lines and Traction Systems); member of the IEEE/PES Transmission and Distribution Committee; member of the PES Awards Committee; past chairman of the PES Fellows Committee; member of the IEEE Fellow Committee; member of the IEEE Electromagnetic Compatibility Society; member of ANSI C63 (Electromagnetic Compatibility); U.S. Representative to CIGRE Study Committee No. 36 (Interference); member of CIGRE; member of the Acoustical Society of America; member of the Bioelectromagnetics Society; and an advisor to EPRI EMI/EMF Projects. He is a National Association of Radio and Telecommunications Engineers (NARTE) Certified Electromagnetic Compatibility Engineer and a registered Professional engineer in the Commonwealth of Pennsylvania.

David E. Blair (SM'91) was born in Potlatch, Idaho on January 8, 1941. He received his B.S. degree in Electrical Engineering from the University of Portland in 1971.

Mr. Blair began working for the Bonneville Power Administration as a student trainee in their Power System Control Branch in 1970. After graduation in 1971, he worked for 10 years in the Division of Materials and Procurement in a wide variety of capacities, but primarily as a Quality Control Representative until 1981 when he transferred to the Division of Laboratories. He has extensive experience in High Voltage Testing and has performed several significant studies of contaminated insulation performance at the BPA 1200-kV Test Site near Lyons, Oregon; the BPA HVDC Test Site near The Dalles, Oregon; and the BPA Laboratory 
Complex in Vancouver, Washington. Over the past few years he has been very active in defining practical test methods for high voltage hardware and transmission lines. He has had considerable experience in High Current Testing of grounding equipment and connections.

Mr. Blair is a member of the IEEE High Voltage Testing Techniques Subcommittee and is a Registered Professional Engineer in the State of Oregon.

Richard D. Stearns (S'76, M'79) was born in Ephrata, Washington on March 4, 1953. He received B.S. and M.S. degrees from Washington State University in 1975 and 1989, respectively.

Mr. Stearns joined the Bonneville Power Administration in 1978. From 1978-1987, he was a member of the technical engineering staff in the Division of Laboratories in Vancouver, Washington. During this time, he was actively engaged in high voltage testing and analytical studies related to transmission line technology including the study of corona and field (electric and magnetic) effects on ac and dc systems. From 1988-1993 he's been with the Division of Electrical and Electronic Engineering in Portland, Oregon. As a senior project engineer, his present duties include transmission line design responsibilities specifically related to corona and field effects.
Mr. Stearns is actively involved in IEEE activities including membership in the Corona and Field Effects Subcommittee and several of it's related working groups and task forces. He is presently serving as an industry advisor to the Electric Power Research Institute and to the State of Oregon's Department of Energy. He has also served as a technical advisor to the Canadian Electric Association.

Douglas J. Lamb (S'71, M'71, M'83) was born in Longview, Washington on August 3, 1949. He received a B.S. degree in Electrical Engineering from Washington State University in 1971 and a M.S. degree in E.E. from that same university in 1974 .

Mr. Lamb joined the Naval Missile Center in 1971 and worked on missile guidance systems until 1973, when he returned to WSU to pursue a Master's degree. In 1976 he joined the Bureau of Mines in Albany, Oregon and worked on instrumentation of metallurgical processes. In 1978 he joined the Bonneville Power Administration working in the Division of Transmission Engineering. He has worked on grounding and lightning protection as it relates to transmission line design and has also worked on underground transmission.

Mr. Lamb is a member of the IEEE Power Engineering Society and a registered Professional Engineer in the State of Oregon. 